\title{
Remote Learning Guidance from State Education Agencies During the COVID-19 Pandemic: A First Look
}

\author{
Justin Reich \\ Corresponding Author: jreich@mit.edu
}

Christopher J. Buttimer, Alison Fang, Garron Hillaire, Kelley Hirsch, Laura Larke, Joshua Littenberg-Tobias, Roya Moussapour, Alyssa Napier, Meredith Thompson, Rachel Slama

\author{
Massachusetts Institute of Technology \\ MIT Teaching Systems Lab \\ tsl.mit.edu/covid19 \\ Last Updated: April 1, 2020
}

Recommended Citation: Justin Reich, et. al. (2020) Remote Learning Guidance from State Education Agencies during the COVID-19 Pandemic: A First Look. Retrieved from osf.io/k6zxy/ 


\section{Executive Summary}

The last week of March 2020 marked a turning point in state-level education policy on remote learning during the novel coronavirus (COVID-19) pandemic. School closures had been announced in all fifty U.S. states, and Kansas was the first to close their schools for the remainder of the year. By Friday March 27, all fifty state education agencies had a COVID-19 webpage or homepage section devoted to policy guidance for closures and remote learning. Approximately $20 \%$ of states had released comprehensive remote learning guidance that addressed issues related to digital versus non-digital options, grading policy, graduation requirements, equity issues, provision of services to students with disabilities, time and schedule recommendations, and suggested resources, lesson plans, and more. With each passing day, more states have released such guidance, often building on the efforts of colleagues in first-moving states. Between March 27 and March 31, we reviewed the guidance from all 50 U.S. state education agencies to provide a summary of issues and challenges and to identify emerging recommendations and best practices.

In many U.S. states, state education agencies primarily fulfill regulatory and technical assistance roles, while teaching and learning guidance typically falls under the purview of local education agencies (LEAs). However, given the extraordinary and rapid changes provoked by school closures and social distancing, many states are providing detailed instructional guidance during this period (see Table 1 for common categories of guidance). Districts can benefit from this guidance, to avoid reinventing wheels and getting too far out of step with neighbors. A handful of state education agencies (Massachusetts, Illinois, and Kansas) have published guidance co-signed by other state stakeholders-representatives from teachers, principals, superintendents, parents, school committees, charter schools, and others—signaling consensus from a broader coalition.

We find substantial areas of agreement in this emerging state policy on remote learning:

- Remote learning support: Nearly all states explicitly recommend or mandate that LEAs offer some form of learning support during school closures.

- Equity and access: State agencies consistently emphasize attention to issues of equity in their guidance to schools. Nearly all states recognize that many families will not be able to access online options, so schools need to find non-digital alternatives using public television, printed packets, or other approaches. States also highlight that students will have differing levels of family supervision to support remote learning.

- Statewide assessments: All 50 states have received an initial federal waiver to bypass statewide assessment requirements. Remote learning time: Of states that have published sample schedules or guidance on daily plans, most have recommended three to four hours of learning activities for older students (including time for exercise and art), with shorter schedules for younger students.

- Attention to a range of student needs: State policy guidance documents encourage LEAs to balance ongoing learning with attending to student needs for food, mental health support, and other issues.

- Attention to special populations: Almost all states have published guidance for students with disabilities. We note that states have not been as rapid to publish guidance related to English learners. We encourage state agencies to provide additional supports for schools serving these learners, as well as guidance for other vulnerable populations such as children in foster care, children experiencing homelessness, and youth in incarcerated settings. 
The most substantial point of divergence in remote learning policy guidance relates to whether LEAs should focus on "enrichment" or "new material." Enrichment approaches emphasize review of previously taught skills, family projects like chores or cooking, and meaningful learning experiences that may not be explicitly aligned with state standards or pacing guides. "New material" approaches recommended that LEAs continue to advance standards-based learning, either by maintaining progress in existing courses (more common at the secondary level) or focusing on a more limited set of critical standards (more common at the primary level). These different perspectives provide an opportunity for states and LEAs to reflect on the purpose of remote learning during a pandemic.

In what follows, we highlight emerging best practices and research-based guidance related to the following recommendations:

- Recommendation 1: Continue to place issues of equity at the center of remote learning plans, with increased guidance for special populations.

- Recommendation 2: Instructional guidance should acknowledge the challenges and constraints of home-based, remote learning.

- Recommendation 3: Communicate information clearly with multiple target audiences in mind.

We have released a public version of our dataset with links, labels, quoted selections, and other noteworthy elements at bit.ly/StateEdCOVID. We will revise and update this dataset in the months ahead. We conducted this analysis in five days, and we apologize in advance to any state education agency where we incorrectly identified any guidance. We invite state education agencies to send us corrections, and updates to be included in the dataset.

The research on education in emergencies suggests that continued schooling and learning can be a protective factor helping young people cope with stress and challenges during periods of disruption. The work of schools in supporting students and providing accessible forms of learning during school closures is more vital than ever. 


\section{Recommendations and Best Practices for State Education Agencies Providing Remote Learning Guidance During COVID-19 School Closures}

\section{Recommendation 1: Continue to place issues of equity at the center of remote learning plans, with increased guidance for special populations.}

- Continue to reinforce equity considerations in policy guidance

- Use guiding principles or reflections tools to evaluate digital divides, accessibility issues, and all elements of remote learning practice (see Vermont's Equity Lens Tool or Minnesota's Equity Lens Reflection and Exploration Tool).

- Nearly every state has emphasized the importance of providing a Free Appropriate Public Education (FAPE) to students with disabilities during school closures. Now, LEAs and schools need more guidance on exactly how to do this at a distance.

- Several states have included statements about the importance of LEAs developing a plan for providing language development instruction for English learners appropriate to their level of English language proficiency. A handful of states have explicitly noted that the LEAs must ensure English learners continue to have equal access to academic grade-level content, and state agencies should develop guidance on how to do this remotely.

- As closures continue, consider how to support other vulnerable populations, such as children facing housing insecurity, children in foster care, and incarcerated students.

\section{Recommendation 2: Instructional guidance should acknowledge the challenges and} constraints of home-based, distance learning.

- Consider how your guidance aligns with the primary divergence in remote learning policy across states: whether to pursue only enrichment and review or to attempt to advance in new standardsaligned material.

- Some states believe that remote learning should leverage "the assets of home-based learning, rather than trying to recreate school" (see New Mexico's Distance Learning Toolkit).

- States that encourage schools and districts to attempt to teach new material might consider suggesting critical standards or topics that are important to subsequent courses (See Alabama's Critical Standards chart).

- Regardless of the immediate approach, consider providing guidance on how schools can offer additional summer school, extended learning time in the fall, or revised courses of study for the 2020-2021 academic year. 
- Consider encouraging a stronger emphasis on asynchronous over synchronous learning

- For households with many family members, competing needs, few devices and/or limited bandwidth, asynchronous learning is more feasible

- As families face job losses and hardships from the recession, synchronous instruction may become more even difficult (See Arkansas, AMI, and Distance Learning).

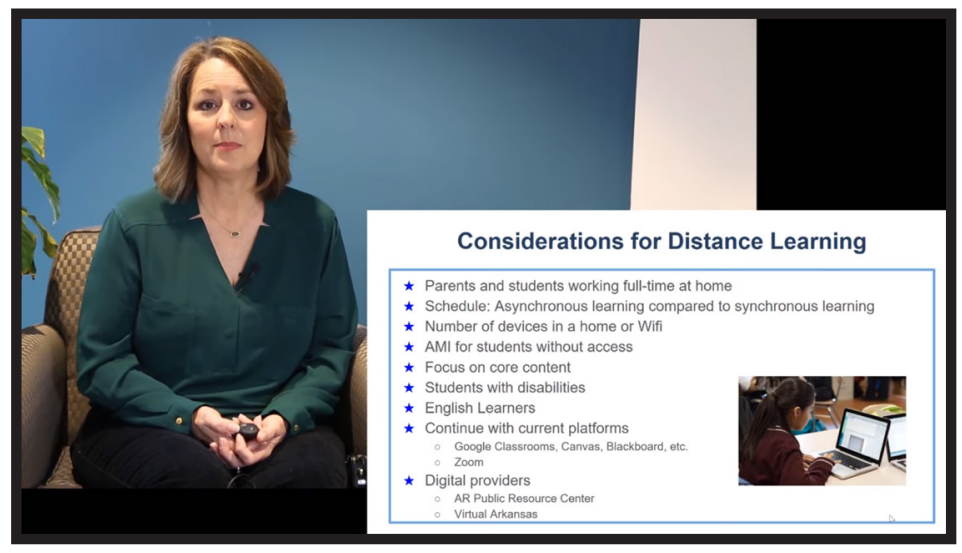

- Consider emphasizing the use of synchronous technologies for office hours or individual check-ins over class instruction

- Consider emphasizing student agency and interest-driven online learning over compliance activities.

- Consider providing guidelines and recommendations for safe and appropriate synchronous video conferencing between teachers, caregivers, and/or students.

- Video conferencing has tremendous potential to maintain social connection during a quarantine but raises new concerns from "zoom-bombing" (unwanted invasions of meeting rooms), to changing teacher work requirements (e.g. turning on video cameras in private spaces), to new concerns for mandated reporting (as teachers see inside children's homes), and risks of inappropriate teacher-student contact. Schools need guidance on these new issues.

- Share example schedules, lessons, and plans from across the state (see district-created examples from Texas).

- When sharing examples, provide a brief summary of what the document is, and what readers might find exemplary.

- Consider having state agencies generate sample units and schedules, in part to provide a reality check on state level policy guidance (See Hawaii's At Home Learning Choice Boards.

- For instance, if a weekly grade-level lesson guide needs to be 1) transmissible by webpage, SMS, phone, and print; 2) accessible to students, busy parents, or caregivers (some of whom may also be school-aged children); and 3) translated into multiple languages, then those constraints can most readily be met with short, simple, and concise learning instructions. State agency staff should identify how easy or difficult it is to follow their own guidance.

- Consider addressing flexibility in graduation requirements and grading policies (See Wisconsin's Graduation Requirements, Grading and Class Promotion).

- Some states are suggesting or mandating that schools use pass/fail or credit/no-credit grading policies (See Delaware's guidance), while others are encouraging grade assignment based on work completed before closure or competency reviews (See Arkansas's three suggested grading policies).

- State university systems should consider issuing guidance on admissions policies, scholarships, and transcripts (See New Hampshire's Policy on Pass/Fail Coursework). 


\section{Recommendation 3: Communicate information clearly with multiple target audiences in mind.}

- Consolidate key information into a small number of documents or webpages

- Create one COVID-19 information page with a prominent link from the state education agency home page.

- Prepare a short, high-level summary of key policies and guidance in one document or webpage for schools and families (see Massachusetts Remote Learning

Recommendations).

- Consolidate information into comprehensive documents or webpages with a linked table of contents, rather than a series of multiple web pages that each contain links to more documents (see the Illinois Remote Learning Recommendations).

- Prioritize accessibility efforts for the key documents, with universal design, recorded phone messages, SMS broadcasts, printed mailings, and translations into multiple languages.

- Consider a short video statement of key policies and values to personalize the work of the state education agency (see Hawaii's Talk Story with Dr. K. or a Video Message from the kitchen of Maine's education commissioner).

- Consider creating a joint statement with key state-level stakeholders including teachers, principals, directors of special education or English learners services, parent-teacher associations, school board associations, superintendent associations, teacher associations, charter school associations, etc. (See Kansas Continuous Learning Task Force Guidance).

- Recognize that addressing extended school closures is a multi-phase process.

- Provide guidance that considers immediate actions along with longer term adjustments for the rest of the school year (See Texas's four phase approach).

- Consider checklists and templates to help schools and districts attend to important issues (See Tennessee's School Closure Toolkit: Academics and Instruction and Minnesota's Distance Learning Plan Template).

- Some states are recommending or requiring that LEAs submit planning documents to identify key areas for guidance and to share best practices.

- Organize policy documents labelled by topic, and timestamp, and then archive outdated information

- Many states published early guidance by date, but documents organized by topic are easier to search. Preserve dated documents as historical artifacts, but consolidate documents by topic, not date; change logs can help readers attend to new information (See Virginia's Guidance change log).

- Continue to collect feedback from students, parents, LEAs, and other key stakeholders. 
Table 1: Frequency counts of state policy statements or resources

\begin{tabular}{llc}
\hline & COVID-19 Guidance Page or Homepage Section & 50 \\
$\begin{array}{l}\text { Models for } \\
\text { Supporting } \\
\text { Stakeholders }\end{array}$ & Resource lists/links & 43 \\
& Frequently Asked Questions (FAO) & 39 \\
& Sample syllabi, weekly plans, units, or lessons & 20 \\
\hline & Cancellation of some or all statewide assessments & 50 \\
\hline & Recommendations to address special education & 45 \\
Reference to federal guidance about special education during the & 41 \\
Consensus & coronavirus pandemic & 41 \\
& Guidance that some form of learning should/must continue & 41 \\
& Recommendation to attend to physical, mental, and/or emotional \\
& needs of children & Recommendation to attend to considerations of equity \\
& Recommendation to consider digital \& non-digital options & 36 \\
\hline
\end{tabular}

\section{Emerging Policy Areas}

\section{Enrichment versus New Material}

Grading and Graduation

English Learners
Statement addressing options to continue teaching new material, limiting instruction to enrichment, either, or both

Recommendations for flexibility in graduation req's

Recommendations for grading policy

Recommendations to attend to considerations of English learners (ELs)

Examples of translations or EL policies/strategies

Request or requirement to submit planning documents

Oversight

Public Broadcasting Scheduled public broadcasting programming

Adressing Privacy

Concerns

Stakeholder

Consensus Building
Guidance to attend to privacy, FERPA, COPPA, PII

Policies or concerns about synchronous video meetings school associations, school boards, etc.) 


\section{Background and Context}

\section{Recent History of School Closures in the United States During the Coronavirus Pandemic}

Metropolitan Seattle was one of the first regions to recognize the presence of a novel coronavirus (COVID-19) in the United States, and on March 4, 2020, the Northshore School District in Bothell, Washington was the first U.S. district to close during the pandemic (Takahama, 2020). After a few days of transition planning, Northshore schools started an online learning model, attempting to replicate the full class day on Monday, March 9. Northshore is an affluent suburban district with high levels of device ownership and broadband access. The first days of the initiative worked reasonably well for older students, but parents of young children reported that elementary students required full time parental supervision to participate in remote learning (Bazzaz, 2020). The Washington Office of the Superintendent of Public Instruction initially cautioned other districts against pursuing a fully online model, in consideration of the many families across Washington lacking sufficient technology access (Reykdal, 2020). These early efforts foreshadowed the crucial questions facing districts now: how much can school proceed online or at a distance, especially in communities with many working parents, few devices, and limited broadband access? Given extended closures, what can schools and districts do to fulfill their mission in these unstable times?

Throughout the middle weeks of March, as COVID-19 spread widely in the U.S., more cities and states began closing schools. Philadelphia initially declared that they would not require distance learning programs for students because it would not be possible for them to do so and provide a free appropriate public education (FAPE) to all students (Wolfman-Arent \& Mezzacappa, 2020). The United States Department of Education (2020) quickly clarified that during a pandemic, schools should try to continue some form of distance learning operation, and while they should try to meet the needs of all students, barriers to meeting those needs should not prevent schools from attempting anything at all. By late March, every state recognized that school systems would require additional guidance for addressing school closures, and all 50 state education agencies published either a designated COVID-19 web page or a section on their home page. By Friday, March 27, approximately $20 \%$ of state agencies had published substantial guidance for local education agencies (LEAs) addressing multiple issues with school closure from meal service to finance issues. In this report, we focus on the early guidance from states on remote learning. Before turning to our methods and findings, we summarize relevant scholarship on three lines of research: digital divides, virtual schooling, and education in refugee and crisis conflicts.

\section{Digital Divides and Digital Learning}

While online learning will undoubtedly play an essential role in remote learning during the coronavirus pandemic, there are several reasons to be seriously concerned about the equity implications of a pivot to online instruction.

Many families with school-aged children lack access to computing devices and broadband. Existing research only partially characterizes these obstacles. A survey of high school students taking the ACT found that one in seven lived in homes with only one computing device for the whole family (Moore et al., 2018). Pew Research (2019) shows that only $56 \%$ of adults living in households earning less that $\$ 30,000$ per year have access to broadband. To our knowledge, there is no survey data that would allow us to more precisely measure readiness for distance learning in a pandemic; we do not know what fraction of households with school-aged children have broadband access and a device for each child. By all indications, however, many school-aged children and their families, especially in rural and urban areas, face serious limits to accessing online learning.

Even when device and broadband access can be secured, a growing body of research suggests that online schooling can come with an "online penalty" for struggling and vulnerable learners (Dynarski, 2018). Recent research from large-scale community colleges (Xu \& Jaggars, 2014), massive open online courses (Hansen \& Reich, 2015), and full-time K-12 virtual schools (J. Ahn \& McEachin, 2017; Fitzpatrick et al., 2020), suggests that many students earn lower grades 
and fail more often in online learning settings compared to on-campus learning experiences. Research from Florida, with a well-established statewide virtual school, shows more mixed outcomes, with positive effects for online modalities on course grades but negative effects on longer term outcomes like follow-on course grades and graduation readiness (Hart et al., 2019). High-achieving learners tend to be minimally affected by online schooling; students who do fine anywhere tend to do fine online. But the online penalty is more severe for vulnerable and struggling students-students with low prior achievement or from disenfranchised ethnic and racial groups. There are good reasons to believe that a pivot to online learning could most negatively affect students living in households that are also most vulnerable to negative effects of recession, food and housing insecurity, and limited access to healthcare in a pandemic.

One important caveat: online learning writ large may not have all the same challenges as online schooling. Researchers studying connected learning (Ito et al., 2012) have documented that when students from all backgrounds engage in interest-driven learning online with a community of supportive peers and mentors, they can produce remarkable works of art, programming, engineering, writing, and more. When motivation and access are high, adolescents and young adults show great proficiency in learning online; unfortunately, student motivation to pursue typically assigned topics in school is not always high.

As challenging as issues of equity are during normal school operations, digital divides will be substantially magnified during the COVID-19 pandemic.

\section{Virtual Schooling and Homeschooling}

Recent research on outcomes from full-time virtual schools aligns with these concerning findings about online learning. Studies of full-time virtual schools in Indiana (Fitzpatrick et al., 2020) and Ohio (J. Ahn \& McEachin, 2017) suggest that students do worse in these schools than in traditional district or charter schools, that the outcomes are most negative for students with low prior achievement, and that negative impacts can last for years.

Even though there are serious concerns about outcomes from full-time virtual schools, there is still much insight that public schools pivoting to remote learning can glean about their operations (Molnar et al., 2019). Most full time virtual schools use "coached homeschooling" models. Teachers provide students and families with a largely asynchronous curriculum, and then students proceed through that curriculum at their own pace. For young learners, a full-time parent or caregiver is expected to provide guidance and support. As students get older, perhaps in high school, they are more capable of working independently. This typically does not take all day. Research and guidance on homeschooling suggests that most homeschool families spend 2-4 hours per day on these schooling tasks (Collom, 2005; Gregory, 2005; Toto, 1994). Virtual school teachers spend limited time, six or fewer hours per week, in synchronous instruction (Molnar et al., 2019). Instead, the best virtual school teachers spend most of their days individually reaching out to students and families to provide coaching, tutorials, and support, making extra efforts to connect with struggling or disengaged students.

These typical models suggest four important implications for remote learning in a pandemic. First, schools and state agencies should assume that young students will require direct supervision to participate in remote schooling-supervision that may not be available from working parents providing essential services. Second, the typical approaches from virtual schools emphasize asynchronous learning. However, the sustained coordination of synchronous class times during a pandemic may prove infeasible. Third, the teacher plays two major roles: curating asynchronous curriculum and providing regular feedback, coaching, and support. This might be a major shift for teachers who see their primary role as providing whole-class, oral, direct instruction. Finally, given the many barriers to online access, the cloistered difficulties of life in a pandemic, and the research on virtual schooling and homeschooling, it may be appropriate to assume that students, especially the youngest students, will not be able to participate in school activities for lengths of time equivalent to a typical school day. 


\section{Education in Emergencies}

For all of the challenges to equity posed by a pivot to online learning, the research literature on education during emergencies suggests that schooling can play an important role in building and reinforcing youth resilience. Studies of schooling during refugee crises and other emergencies suggest that establishing routines, providing intellectual stimulation, and maintaining relationships with peers and trusted adults can all be protective factors helping young people cope with an emergency (INEE, 2016). Schools have a vital role to play in the coronavirus pandemic; attention to issues of equity can help us ensure that schools focus their efforts on students with the greatest needs and challenges.

\section{Research Questions}

Taken together, this research clarifies not only the substantial challenges that schools face, but also the important roles they play during the coronavirus school closures. These considerations inform the research questions that we address in our analysis of the initial remote learning guidance from the 50 U.S. state education agencies:

- What are key points of consensus that states address in their remote learning guidance?

- How do states advise LEAs in terms of digital and non-digital remote learning?

- How do states balance enrichment and review with forward progress?

- How do states address LEA obligations to students with special needs and English learners?

- How do states address grading, credit hours, graduation for seniors, and college admissions and scholarship?

- In these early days, what approaches appear to be particularly useful or noteworthy in supporting schools and families with remote learning?

\section{Methods}

Starting on March 27, we examined the websites of all 50 U.S. state education agencies and began analyzing their COVID-19-related remote learning guidance for schools, districts, students, and families. The lead author reviewed materials from all fifty states and developed a set of coding criteria. These coding criteria were derived from concerns raised by the research above, from a grounded theory (Charmaz, 2014) approach to identifying issues salient to state agencies, and from informal discussions with teachers, school leaders, education journalists, and state policymakers over the course of March 2020. After an initial scan and development of coding criteria, additional researchers provided a more comprehensive review of state documents and contributed to coding. Some coding disagreements were reviewed in discussion, but most labels were designated by a single researcher (a more comprehensive effort revising our labels and measuring interrater reliability would be a worthy next step for future research). We made efforts to track updates to state education agency sites between March 27 and the end of the day on March 31 when we ceased new analysis, but undoubtedly we missed some updates during this dynamic period.

We address our research questions through two primary analytic methods. First, we count the presence or absence of state guidance on a number of key issues in order to identify areas of consensus and divergence, as well as emerging areas of policy concern (see Table 1). Second, we analyze case studies of particular state recommendations, guidance, and resources that are well-aligned with prior research, noteworthy for their clarity or effective execution, or significant in raising new questions not commonly addressed by other states. 
We present the research that follows as a rapid, imperfect "first look" at emerging issues in state education policy during a pandemic. We have published a March 31 snapshot of our dataset at osf.io/k6zxy/, and we also have published an open version of our dataset that the public can comment on and correct at bit.ly/StateEdCOVID. When examining these data, we discourage readers from inferring that an absence of guidance from a particular state on a particular issue represents an absence of concern from those state policymakers on that issue. State agencies may be communicating with local education agencies outside of website communications; they may be listening to stakeholders and preparing guidance; and our research team may have simply missed guidance among the hundreds of web pages that we read over five days.

\section{Findings}

\section{Key Points of Consensus in State Education Policy Guidance}

We identified seven key points of consensus found in the guidance of 35 or more states. All states have received an initial federal waiver to bypass requirements around statewide assessments. Nearly all states recommend that some form of learning should or must continue. Most states acknowledge that this learning will need to be provided through both digital channels, like online tools, and non-digital channels, like broadcast television (e.g. new PreK-12 educational programming and schedules from New York's nine PBS stations ${ }^{1}$ ), SMS messages, phone calls, and printed packets. States are clear that any efforts to provide education must also address students with special education needs. Most states reference or link to federal guidance explaining that schools should try to provide learning opportunities during school closures that adhere to free appropriate public education (FAPE), but that limitations or barriers to meeting special education needs do not prevent LEAs from pursuing remote learning (USDOE, 2020).

States also expressed concern and emphasized the importance of the physical health, mental health, and emotional needs of students. As West Virginia noted on March 25, 2020, "Feeding children is our number one priority." ${ }^{2}$ State agencies also consistently emphasized addressing multiple dimensions of equity-digital divides, special education needs, needs of English learners, and concerns of the homeless and vulnerable-as schools pivot to remote learning. Delaware's state education agency, echoing prior guidance from Massachusetts, wrote,

"Equity needs to be a top consideration in local planning efforts, especially as districts and charters make plans to manage an extended closure. This crisis disproportionately affects our most-vulnerable students, their physical and mental health as well as their academic outcomes." 3

\section{Guidance for Digital and Non-Digital Learning Options}

Most state guidance makes clear that remote learning for families with computing devices and broadband connections has the potential to look very different than for families without these resources. State agencies are directing families to new free or low-cost internet services while providing guidance about safe ways for schools to distribute laptops and other devices. For digital options, some states are encouraging districts to set up a learning management system as a central clearinghouse for dissemination of information and learning materials to families. Many states are publishing lists of resources, websites, and subscription services that address learning needs across grade levels and content areas. The guidance about these services sometimes

\footnotetext{
${ }^{1}$ New York State Education Department. (2020). PBS Live Broadcasting. http://www.nysed.gov/edtech/pbs-live-broadcasting

${ }^{2}$ West Virginia Department of Education. (2020). Coronavirus 19 Information https://wvde.us/covid19/

${ }^{3}$ Delaware Department of Education. (2020). Supporting Continuity of Learning in Delaware Schools. https://www.doe.k12.de.us/cms/lib/DE01922744/Centricity/Domain/599/continuity of learning.pdf
} 
embeds two, seemingly conflicting messages: there is an incredible array of options available, but schools and teachers should strive to keep things simple. Some states recommend that schools and districts focus on using their existing, established technology infrastructure, while only adding new services when necessary.

Four issues with digital learning models stand out as prominent points of discussion. First, some guidance encourages schools to consider the right balance of asynchronous and synchronous learning. While some schools or districts might be trying to replicate their existing schedule of synchronous meeting times, several state agencies explicitly caution against this approach, since coordinating the meeting times of students, parents/caregivers, and teachers (who are often addressing the needs of their own children) makes this approach very difficult and perhaps unsustainable. Vermont explicitly recommends limiting synchronous learning time to 1-2 hours per day, for example. ${ }^{4}$

The widespread use of synchronous video also raises a host of new issues for schools. Video conferencing has tremendous potential to maintain social connection during quarantine. However, it raises new concerns, from "zoom-bombing" (unwanted invasions of meeting rooms) to changing teacher work requirements (turning on video cameras in private spaces) to new mandated reporting issues (as teachers see inside children's homes) and risks of inappropriate teacher-student contact. Schools need guidance on these new challenges. Some states like New Hampshire provided example waivers for students and teachers to use, ${ }^{5}$ and others like Kansas caution specifically against one-to-one video conferencing between teacher and student. ${ }^{6}$ States need to research and monitor this issue and provide ongoing guidance.

We found at least 20 state education agencies with language reminding LEAs to adhere to privacy guidelines established by the Family Educational Rights and Privacy Act (FERPA), the Children's Online Privacy Protection Act (COPPA), and other relevant laws and regulations. Ideally, adopting new school technologies would be a thoughtful, considered process that carefully evaluates vendor terms of service and privacy policies (Plunkett \& Gasser, 2016); however, this is challenging during an emergency. Some state agencies also include a disclaimer with their list of digital resources, such as New Hampshire's warning that they have "not vetted the below resources for compliance with New Hampshire minimum standards for privacy and security under RSA 189:66 or any relevant state or federal statutes, including but not limited to the ADA, FERPA, HIPAA, Schools are advised to review all apps and websites for compliance" (New Hampshire Department of Education) ${ }^{7}$, leaving such vetting to individual institutions and educators.

These digital challenges are substantial, but state agencies are also asking schools to simultaneously develop a parallel set of non-digital options for learners. There are three major categories of approaches to non-digital home learning. Perhaps the most commonly represented approach is "worksheet packets." Schools are encouraged to curate, print, and distribute-by mail, school bus service, or family pickup site-paper packets of learning materials. Given the dim reputation of worksheets and packets among many educators and families, a number of states are also proposing a second approach where students do learning activities with their families: e.g., walk and observe nature, cook meals, do chores around the house, or plant a garden as the winter turns to spring. Rather than try to do school learning in ill-equipped home environments, the idea is to maximize the kinds of learning that naturally happens at home. A third approach is to closely partner with public broadcasting stations. In Arkansas, for example, the local PBS stations will provide scheduled programming for students in grades $\mathrm{K}-2,3-5$, and 6-8, and each grade band gets 90 minutes of programming a day (see Figure 1). ${ }^{8}$ The state also provides additional

\footnotetext{
${ }^{4}$ Vermont Agency of Education. (2020). Transitioning to Remote Learning. https://education.vermont.gov/sites/aoe/files/documents/edu-transitioning-to-remote-learning.pdf

${ }^{5}$ New Hampshire Department of Education. (2020). Sample Student Release Form. https://www.education.nh.gov/sites/g/files/ehbemt326/files/sample-student-release-form.pdf

${ }^{6}$ Kansas Department of Education. (2020). Continuous Learning Task Force. https://www.ksde.org/Portals/0/Communications/Publications/Continuous\%20 Learning\%20Task\%20Force\%20Guidance.pdf?ver=2020-03-19-084325-833

${ }^{7}$ New Hampshire Department of Education. (2020). Remote Instruction. https://www.education.nh.gov/who-we-are/division-of-educator-and-analytic-resources/bureau-of-educational-opportunities/public-school-approval-office/remote-instruction

${ }^{8}$ Arkansas Department of Education· (2020). Alternative methods of instruction http//dese-ade-arkansas'gov/divisions/earning-services/alternative-methods-ofinstruction
} 
digital resources and proposed schedules for families to plan the rest of the day around the grade band television. By staggering programming families—especially those with television but no broadband-can get a reliable daily schedule and coordinate homeschooling, screen time, and other activities.

Curriculum development that meets the diverse needs and interests of a classroom of students is difficult during normal school operations. Developing parallel curricula for digital and non-digital remote learning during a pandemic will be a substantial challenge for school systems, and many state education leaders encourage schools and teachers to foreground simplicity in their planning.

\begin{tabular}{|c|c|c|c|c|c|c|}
\hline \multicolumn{7}{|c|}{ WEEKLY SCHEDULE } \\
\hline & Example & Monday & Tuesday & Wednesday & Thursday & Friday \\
\hline 8:00 am & & \multicolumn{5}{|c|}{ Ready, Set, Go! Wake up, eat breakfast, and get dressed for the day! } \\
\hline \multicolumn{7}{|l|}{$9: 00 \mathrm{am}$} \\
\hline $9: 30 \mathrm{am}$ & & \multicolumn{5}{|c|}{$\begin{array}{l}\text { Watch Grades 3-5 Arkansas PBS } \\
\text { 9:30-11:00 each day }\end{array}$} \\
\hline $11: 00$ & Literacy & & & & & \\
\hline $\begin{array}{l}12: 00 \\
\mathrm{pm}\end{array}$ & Lunch & & & & & \\
\hline $1: 00$ pm & Play & & & & & \\
\hline \multicolumn{7}{|l|}{$2: 00 \mathrm{pm}$} \\
\hline \multicolumn{7}{|l|}{$3: 00 \mathrm{pm}$} \\
\hline $4: 00 \mathrm{pm}$ & Math & & & & & \\
\hline $5: 00$ pm & $\begin{array}{l}\text { Fun } \\
\text { Zone }\end{array}$ & & & & & \\
\hline \multicolumn{7}{|l|}{$6: 00 \mathrm{pm}$} \\
\hline $7: 00 \mathrm{pm}$ & & \multicolumn{5}{|c|}{$\begin{array}{l}\text { Great time to start getting ready for bed. } \\
\text { Once you're ready, it's a great time to snuggle with a book. }\end{array}$} \\
\hline $8: 00$ pm & & & & & & \\
\hline
\end{tabular}

Grades 3-5, Week 1

Page 4

Figure 1: Arkansas schedule planner for grades 3-5 with PBS programming. [A weekly schedule titled Arkansas AMI Learning Guide with the days of the week on the top row, hourly times from 8am to 8pm. In the 8am row is written "Ready, Get set, Go! Wake up, eat breakfast, and get ready for the day!". On the schedule at 9:30am for every weekday is written "Watch Grades 3-5 Arkansas PBS 9:30-11 each day". On the schedule at 7pm for every weekday is written "Great time to start getting ready for bed. Once you're ready, it's a great time to snuggle with a book."] 


\section{Diverging Approaches: Enrichment and Review Versus New Material and Forward Progress}

The primary area where we found divergence in state guidance relates to the goals of remote learning during school closures. Some state agencies are hoping to continue forward progress through new material from standards-aligned curriculum. Texas, for instance, describes their efforts as helping "districts launch 'at-home schools' that maximize the amount of instructional time for students this school year and support student mastery of grade level standards." ${ }^{10}$ Alabama has proposed a set of critical standards for K-8 teachers to use in focusing instruction during school closures. ${ }^{11}$ By contrast, some states argue for an emphasis on skills review, projects, and similar activities categorized as "enrichment." New Mexico's early guidance suggests that home is not the place to try to recreate school, and instead school divisions should focus on supporting home-based learning:

"Leveraging the assets of home-based learning, rather than trying to recreate school, can provide meaningful learning experiences that connect to students' home lives, interests, and identities. Trying to support school-like learning in a home setting may frustrate teachers, students, and families. Educators should consider how to give students agency to pursue learning that is relevant to them via resources that are available at home and with meaningful family engagement as possible." 12

Some states stake out a position on these issues, and others simply highlight these as potential approaches. Nebraska suggests that these approaches might proceed in phases:

leaders encourage schools and teachers to foreground simplicity in their planning.

"If possible, school districts/school systems should consider a layered approach.

This means if a district/school system is providing short-term enrichment opportunities, the school district/school system may also develop a plan that moves from providing only enrichment opportunities to providing educational opportunities.--starting with enrichment before strengthening remote learning systems and turning to new material." 13

Issues of time and schedules are closely connected to these questions of enrichment and progress. Massachusetts offers the blanket guidance that schools should prepare learning activities that would take up about half of a typical school day, including daily time for art and exercise. ${ }^{14}$ Kansas recommended limits that expand by grade band: "Pre-K : 30 minutes; Grades K-1: 45 minutes; Grades 2-3: 60 minutes; Grades 4-5: 90 minutes; Grades 6-12: 30 minutes per teacher (3 hours max in a day)." ${ }^{15}$ These guidelines align with typical schedules followed by voluntary homeschool families. We did not find any guidance, even among states with the most ambitious rhetoric around maintaining forward progress, for trying to maintain typical, full-day, school schedules.

\footnotetext{
${ }^{9}$ Arkansas Department of Education. (2020). Alternate Methods of Instruction, Grades 3-5, Week 1. http://dese.ade.arkansas.gov/public/userfiles/Learning Services/Alternative_Methods_of_Instruction/3-5_AMI_Week_1.pdf

${ }^{10}$ Texas Education Agency. (2020). District Instructional Continuity Planning Overview https://tea.texas.gov/sites/default/files/district instructional continuity_planning_intro_march_20_2020.pdf

${ }^{11}$ Alabama State Department of Education. (2020). K-8 Critical Standards. https://drive.google.com/file/d/1ZufRLahwj884iLKjpOEp516EX-L1zNjP/view

${ }^{12}$ New Mexico Public Education Department. (2020). Supporting Students' Learning During COVID-19 School Closures with Distance Learning. https:// webnew.ped.state.nm.us/wp-content/uploads/2020/03/Educators-Distance-Learning-Toolkit_Final.pdf

${ }^{13}$ Nebraska Department of Education. (2020) Continuity of Learning Plans Guidance Document. https://cdn.education.ne.gov/wp-content/uploads/2020/03/ Statement-on-Continuity-of-Learning-3.27.2020.pdf

${ }^{14}$ Massachusetts Department of Elementary and Secondary Education. (2020). Remote Learning Recommendations During COVID-19 School Closures. http://www.doe.mass.edu/covid19/2020-0326remote-learning.docx

${ }^{15}$ Kansas Department of Education. (2020). Continuous Learning Task Force https://www.ksde.org/Portals/0/Communications/Publications/Continuous\%20 Learning\%20Task\%20Force\%20Guidance.pdf?ver=2020-03-19-084325-833
} 
The case for continuing to address new material is that if as many students as possible make as much progress as possible, then the needs for later remediation may be lessened. In places with widespread capacity to support remote digital learning, it may be feasible to help many students advance and later provide targeted supports to less privileged students in the fall. In places where few students can keep up with a distance curriculum, efforts to move forward might cause teachers and families to experience more stress and angst than positive learning outcomes.

By contrast, students pursuing enrichment, freed from the constraints of standards-based learning, might have more time to focus on connected learning, hobbies and interest-driven projects. They might finish the quarantine period having developed valuable new life skills or personally-relevant knowledge. On the other hand, they may experience the equivalent of an extended period of summer learning loss (Sandberg Patton \& Reschly, 2013), with particularly negative effects for students who struggle on standardized tests and other gatekeeping experiences.

In education, policy differences that appear wide at the state level can materialize modestly in practice; as historian Larry Cuban observes, teachers often "hug the middle" on pedagogical questions (Cuban, 2009). Local conditions of technology access and school culture may determine teacher practice more than state pronouncements. And state guidance also leaves rooms for flexibility, exceptions, and multiple interpretations. For instance, Massachusetts "strongly recommend that districts and schools focus on reinforcing skills already taught this school year and applying and deepening these skills" (emphasis in original). ${ }^{16}$ In the next sentence, they also "recognize that in some cases, teachers and students may wish to continue with new material, particularly at the high school level." On the other side, Virginia offers the following guidance to high schools in targeting their teaching for the fourth quarter:

"School divisions should focus efforts on:

- identifying the specific required content that had not been taught as of Friday, March 13, 2020; and

- developing learning modules to address the missing content necessary for awarding standard credit with a particular focus on content that is essential for success in subsequent coursework." ${ }^{17}$

Virginia also makes clear that the stakes of learning efforts during closures should be low: "The school division's plan to address missing content should not prevent student promotion to the next grade level or next sequential course."

Considering issues of enrichment versus new material may help states or schools answer the underlying question: "What is the goal of remote learning in a period of extended school closure?" Our own view is that the research on online schooling and online learning suggests that interest-driven enrichment approaches may prove to be more generative for student learning and well-being than efforts to maintain progress on standards-aligned materials. However, we also believe that at the end of the quarantine there will be exemplars and cautionary tales from both models; often in education it is more important to get one system right than to pick the one right system. Schools or states that identify with one model or another may find it useful to share materials and engage in conversations with other educators adopting similar approaches. Regardless of what model or combination of models schools choose, the serious disruption from this spring will necessitate thoughtful planning and redesign of the 2020-2021 school year.

\footnotetext{
${ }^{16}$ Massachusetts Department of Elementary and Secondary Education. (2020). Remote Learning Recommendations During COVID-19 School Closures. http://www.doe.mass.edu/covid19/2020-0326remote-learning.docx

${ }^{17}$ Virginia Department of Education (2020). Guidance on Graduation Requirements, Awarding of Credits, and Continuity of Learning. http://www.doe.virginia.gov/support/health_medical/office/covid-19-grad-credits.shtml
} 


\section{Addressing Diverse Needs of Learners During School Closures}

Nearly all states have published guidance encouraging schools to do their best to provide all students with a free and appropriate public education. Perhaps unsurprisingly, very few states have offered any detailed guidance or particularly promising models of how this might be done. State primarily have suggested technology tools that can be used to make curriculum materials more accessible (for instance, North Dakota highlights the translations in Khan Academy, the potential applications of Google Translate, and the use of synchronous video for small group instruction ${ }^{18}$ ). Some states have suggested that in limited cases, school buildings might be used to provide instruction to small groups of socially distanced students with the highest need. Many states have promised forthcoming guidance on teletherapy and other approaches addressing students with disabilities, and they are offering webinars and other venues to share new practices.

Generally speaking, as researchers we have been enormously impressed with the careful yet rapid work conducted by state agencies around the country, but there is one area where we urge our colleagues to accelerate their efforts: attention to the needs of English learners (ELs). We identified only 21 states that specifically reference ELLs in their policy guidance, and only 9 that modeled sample lessons and translations. Schools' legal obligation to English learners is no less than their obligation to students with other special needs. We encourage other states who have not yet centered the needs of English learners to continue to share materials in multiple languages, partner with content developers on translations, and build peer networks among multilingual families and teachers to provide translation help and support.

In addition to students with disabilities and language learners, state education agencies should continue to generate new guidance for supporting a variety of vulnerable populations. Minnesota's offers an excellent first effort at providing guidance for students experiencing housing insecurity and recommending coordination with local and regional tribal leaders. ${ }^{19}$ Mississippi offers brief initial guidance for youth in foster settings and in detention. ${ }^{20}$ We are particularly concerned with the health and safety of youth in incarcerated settings, and we urge state education agencies to weigh in on their behalf (Schindler \& Schiraldi, 2020).

\section{Case Lesson: Social Studies in San Antonio}

The Texas Department of Education has shared a number of exemplar lessons from districts, including from the San Antonio Independent School District. ${ }^{21}$ The daily lessons are presented on two slides, one in English and one in Spanish (See Figure 2). The activities are estimated to take about three hours, about half of a typical school day. One 11th/12th grade Social Studies lesson caught our attention: a suggestion to interview a family member about an important historical event and write a thank-you note explaining what the student learned. While not clearly aligned with any particular standards, the lesson has several attractive features for learning during an extended school closure: instructions are short but the possibilities of extension are wideone can imagine that the students who enjoy the exercise might continue to interview other family members. The assignment promotes social and familial connectedness and allows students to pursue their interests. Finally, it is easily translated in multiple languages, and would fit in one or two SMS messages for those with limited internet access. In many contexts, these kinds of simple-yet- rich, extensible, interest-driven, skillsbased activities may prove to be the most valuable in a pandemic.

\footnotetext{
${ }^{18}$ North Dakota Department of Public Instruction. (2020). School Closure Guidance for Public School Districts and Non-Public Schools: Process Toolkithttps://www.nd.gov/dpi/sites/www/files/documents/Academic\%20Support/Process\%20Toolkit\%20Version\%20March\%2030.pdf

${ }^{19}$ Minnesota Department of Education. (2020). School Closure Guidance for Public School Districts and Charter Schools. https://education.mn.gov/ mdeprod/idcplg?IdcService=GET FILE\&dDocName=MDE032114\&RevisionSelectionMethod=latestReleased\&Rendition=primary

${ }^{20}$ Mississippi Department of Education. (2020). Updates and Information in Response to COVID-19 (Coronavirus) https://www.mdek12.org/COVID19
} 


\section{Day 3}

\section{Math}

The amount of medicine (mg) in the bloodstream of a patient $t$ hours after an injection decreases

exponentially. Use the graph below to estimate

$f(1 / 3)$ and explain what it tells us in this situation.

Time: (15 $\mathrm{min})$

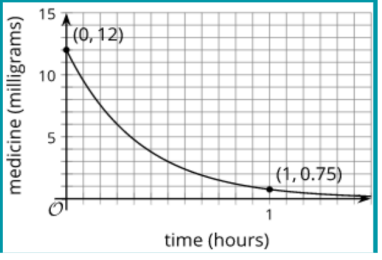

Physical Fitness

Repeat 10 times

College, Career and Military

Readiness

Steps to Access Skills to Succeed. Use this

code (40SAge) to register

to complete a Skills to Succeed

Module 2 "Why do you want to be a....?
Reading-Language Arts

Option 1: Read about studying kindness.

Answer the questions at the end of the article, and

discuss the ideas that surprised you or challenged or

confirmed what you already knew with someone at

home.

Option 2: Find a book to read, any book that interests you, or continue reading a book. Read for 30 minutes and discuss what is happening in the book with someone in your home. What do you have questions about? What do you think will happen next?

Time: (30 $\mathrm{min})$

$=$

\section{Science}

Research the advantages and disadvantages of hydroponic gardening and write a letter to the mayor of San Antonio describing whether or not the city should invest in hydroponic gardening based on the information you discovered in your research.

Time: (30 $\mathrm{min})$

\section{Social Studies}

With a family member, discuss a significant historical event that they experienced. Ask about how this event changed his or her life and what he or she learned from it.

After your conversation, write a thank you note or message to this family member that shares what you learned.

Time: $(30 \mathrm{~min})$

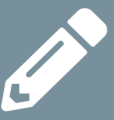

\section{Fine Arts}

Option 1: Character Study involves creating and internalizing the details of a character's life. Use this link, select an image and answer the questions below.

Option 2: Click on this link DudamelMambo Mambo is one movement from this major work. What is the title of this original work? Who is the composer? Time: $(20 \mathrm{~min})$

\section{Día 3}

\section{Matemáticas}

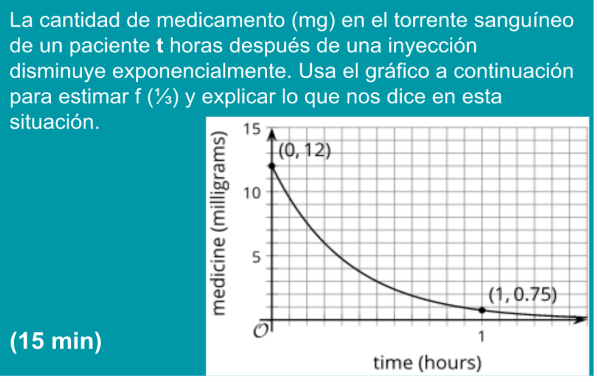

\section{Condición física}

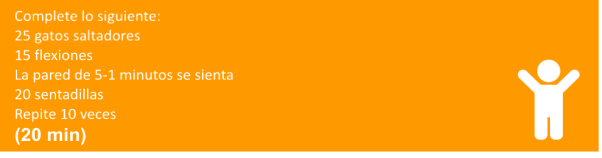

\section{Preparación universitaria,}

profesional y militar

Pasos para acceder a Skills to Succeed. Utilize esta código (40SAge) para registrarse en este sitio y completa Skills to

Succeed Módulo 2 "Why do you want to be a..."

\section{Lectura y escritura}

Opción 1: Lee este

Este artículo me gusta/me sorprende

porque... Quiero saber más acerca

de...Opción 2: Lee un libro que te interesa

por 20 minutos

Escogi este libro porque...

Me interesa leer acerca de

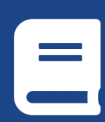

\section{Ciencias}

Investigue las ventajas y desventajas de la jardinería hidropónica y escriba una carta al alcalde de San Antonio describiendo si la ciudad debería invertir o no en jardineria hidropónica según la información que descubrió en su investigación.

(30 min)

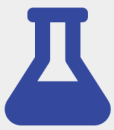

\section{Estudios sociales}

Con un miembro de la familia, discuta un evento histórico significativo que hayan experimentado. Pregunte cómo este evento cambió su vida y qué aprendió de él.

Después de su conversación, escriba una nota o mensaje de agradecimiento a este miembro de la familia que comparta lo que aprendió.

(30 min)

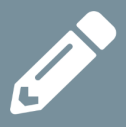

\section{Bellas artes}

Opción 1: El estudio de personajes implica crear e internalizar los detalles de la vida de un personaje. Use este enlace, seleccione una imagen y responda las preguntas a continuación.

Opción 2: Haz clic en

Mambo es un movimiento de este gran trabajo.

¿Cuál es el título de esta obra original? ¿Quien es el compositor?

(20 minutos)

Figure 2: Daily lesson plans for 11th and 12th grade students, in English and Spanish, from San Antonio Independent School District

\footnotetext{
${ }^{21}$ San Antonio Independent School District. (2020) Digital Playground. Online Learning at Home· Grades 11-12. https://docs.google.com/presentation/d/e/2PACX-1vStxAMrSb2rhNdvlhi16jVepSVpDHQjq8fr2A2DrKJwzad5mMuZ9Y6a4Vavgfix8c9JBxwi2UOCY6fm/pub?start=false\&loop=false\&delayms=3000\&slide=id.g7182f84166 $5 \quad 17$
} 


\section{Addressing Bureaucracy and Policy with Flexibility and Grace: Grades, Graduation, Credit Hours, and College Admissions and Scholarships}

Encouragement for flexibility—what the Kansas state education agency calls "grace" 22_is widespread in state COVID-19 guidance. In a state-recommended video, Montana's two recent teachers of the year remind their colleagues that calving season is underway and older students in rural areas may need to address these bovine responsibilities, as well as child care for younger siblings, alongside their schooling. ${ }^{23}$ Guidance across multiple states particularly calls for flexibility with immediate bureaucratic concerns related to graduation requirements for seniors, the assignment of credit hours for foreshortened courses, and grading.

An emerging consensus is that schools should make new accommodations to help seniors graduate. Georgia offers the strong statement: "GaDOE has issued guidance to school districts to ensure no senior will be held back from graduating on time due to the COVID-19 school closures." ${ }^{24}$ Several states, such as New York and Alabama, recommend giving full credit to students who were passing courses as of the spring mid-term, and Alabama and others also promote the use of online credit recovery programs. As with so many issues in school closures, these programs raise issues of equity and access, as students failing courses are disproportionately from poverty-impacted neighborhoods that may lack online access to these programs. New Mexico recommends a competency-based approach to awarding credits, including opportunities for: "Passing a locally designed test, - Completing a locally designed series of assignments, - Achieving a set cut score on a college entrance exam, - Demonstrating applied work experience." 25

Some states have encouraged school districts to dispense with grades altogether for the period of school closure, and here we see evidence that state agencies are beginning to borrow and share policies amongst each other. Massachusetts ${ }^{26}$ and Delaware ${ }^{27}$, for instance, use very similar language in encouraging schools to use credit/no credit where grades are necessary, and to avoid assigning no credit to students. Other states encourage flexibility in making up missed work and assigning grades.

One of the primary purposes of assigning grades in high school is to support colleges in making admissions and scholarship decisions. Presumably, in the months ahead, state college systems with selective enrollment will need to provide additional guidance to students and families. Already, a few states have offered guidance about various merit scholarship programs tied to grade point average or test scores. Florida 's state agency clarified that their "Bright Futures scholarships shall be based on available data and results" (i.e. from before closures). ${ }^{28}$ Georgia's state university system will go SAT/ACT-optional for one year. The University of New Hampshire system has released initial guidance emphasizing that they expect to see Pass/Fail grades on future applications, and they will review future scholarship applications to attend to consideration of how Pass/Fail grades will affect GPAs. They note: "The University System of $\mathrm{NH}$ is committed to ensuring that nothing COVID-19-related will negatively impact a student's enrollment or future enrollment." 29

\footnotetext{
${ }^{22}$ Kansas Department of Education. (2020). Continuous Learning Task Force. https://www.ksde.org/Portals/0/Communications/Publications/Continuous\%20 Learning\%20Task\%20Force\%20Guidance.pdf?ver=2020-03-19-084325-833

${ }^{23}$ Montana Department of Education. (2020). Remote Learning: Tips from Montana Teachers of the Year. https://youtu.be/xovpiFIpFdo

${ }^{24}$ Georgia Department of Education. (2020). Graduating Seniors. https://www.georgiainsights.com/graduating.html

${ }^{25}$ State of New Mexico· (2020). School Closure FAQ https//www'newmexico-gov/education/school-closure-fad

${ }^{26}$ Massachusetts Department of Elementary and Secondary Education. (2020). Remote Learning Recommendations During COVID-19 School Closures.

http://www.doe.mass.edu/covid19/2020-0326remote-learning.docx

${ }^{27}$ Massachusetts Delaware Department of Education. (2020). Supporting Continuity of Learning in Delaware Schools. https://www.doe.k12.de.us/cms/lib/ DE01922744/Centricity/Domain/599/continuity of learning.pdf

${ }^{28}$ Florida Department of Education (2020). Florida Department of Education Announces Additional Guidance for the 2019-20 School Year. http://www.fldoe. org/newsroom/latest-news/florida-department-of-education-announces-additional-guidance-for-the-2019-20-school-year.stml

${ }^{29}$ University System of New Hampshire. (2020). Policy on Pass/Fail Coursework. https://www.education.nh.gov/sites/g/files/ehbemt326/files/inline-documents/2020/usnh-passfail.pdf
} 


\section{Effective Modes of Communicating}

Given the diverse constituencies that state agencies address-students, families, teachers, school boards, superintendents and so on-states are publishing their guidance in multiple formats. Having reviewed the portfolios of all fifty states, we identified a few genres of bureaucratic communication that were particularly useful.

Commissioner Video Messages. From Maine to Hawaii, state commissioners have begun posting short videos that convey important messages and put a human face to the work of agencies. From Pender Makin's kitchen in Maine ${ }^{30}$ to the traditional talk story of Hawaii's Dr. K. ${ }^{31}$, we found these short messages moving and humanizing.

High-Level Summaries. At the risk of betraying a hometown bias, we found the Massachusetts Remote Learning Recommendations to be a valuable model for communicating high-level principles. ${ }^{32}$ The main recommendations are only three pages long, but they comprehensively address many core issues of equity, expectations, schedules, planning, technology, grading, and feedback, and they communicate this information in ways accessible to educators and families alike. Co-signed by teachers unions, the school board association, the state parent teacher association, the state charter association, and the superintendent's association, the document conveys a statewide consensus of priorities even in the absence of legally-binding force. For states that have distributed their initial guidance across multiple documents and memoranda or in more comprehensive guides, it may be a good time to consider publishing a concise, collaborative statement of principles.

Comprehensive Guidance. Illinois ${ }^{33}$ and Kansas $^{34}$ provide useful models of more comprehensive guidance from task forces made up of multiple education stakeholders in documents of 60 and 74 pages, respectively. These more complete documents start with short statements of principles similar to Massachusetts, and they then provide consolidated reference materials and policy guidance for many detailed topics in a single PDF. Especially for states that have been publishing their guidance in dated memoranda, we recommend transitioning to a more consolidated model where guidance is organized by topic rather than by date.

Templates and Checklists. Several states are requesting or requiring LEAs to submit plans and forms of various kinds in order to grant waivers, identify common challenges, and find and share best practices. The Tennessee School Closure Checklist for Districts ${ }^{35}$ and the Minnesota Distance Learning Plan Templates ${ }^{36}$ offer models for how state policy guidance can be encoded into questions and planning documents. State education agencies might consider adapting these kinds of tools to assist LEAs in their immediate planning or in monitoring progress and refining their operations as closures continue.

Phased Approaches. Several states are structuring their planning around a phased approach, recognizing that schools need time for planning, a period of initial implementation, and then ongoing work to iteratively improve newly forged systems. The guidance from Texas is organized around a series of four phases in implementing their "At-Home" model (see figure 3) ${ }^{37}$. States that have focused on immediate guidance may consider planning for what comes after a rapid pivot to distance learning

\footnotetext{
${ }^{30}$ Pender Makin. (2020). Message from the Commissioner. https://www.youtube.com/watch?v=yF562moqlyY

${ }^{31}$ Hawaii Department of Education. (2020). Talk Story with Dr. K.: Welcome Back.https://vimeo.com/400380847

${ }^{32}$ Massachusetts Department of Elementary and Secondary Education. (2020). Remote Learning Recommendations During COVID-19 School Closures.

http://www.doe.mass.edu/covid19/2020-0326remote-learning.docx

${ }^{33}$ Illinois State Board of Education. (2020). Remote Learning Recommendations During COVID-19 Emergency. https://www.isbe.net/Documents/RL-Recommendations-3-27-20.pdf

${ }^{34}$ Kansas Department of Education. (2020). Continuous Learning Task Force. https://www.ksde.org/Portals/0/Communications/Publications/Continuous\%20 Learning\%20Task\%20Force\%20Guidance.pdf?ver=2020-03-19-084325-833

${ }^{35}$ Massachusetts Tennessee Department of Education. (2020). Tennessee School Closure Checklist for Districts. https://www.tn.gov/content/dam/tn/educa$\underline{\text { tion/health-\&-safety/Academics_Toolkit_3.23.20.pdf }}$

${ }^{36}$ Florida Minnesota Department of Education. (2020). Minnesota Distance Learning Plan Templates. https://education.mn.gov/mdeprod/idcplg?IdcService=GET_FILE\&dDocName=MDE032166\&RevisionSelectionMethod=latestReleased\&Rendition=primary

${ }^{37}$ Texas Education Agency. (2020). Instructional Continuity Framework Detailed Guidance. https://tea.texas.gov/sites/default/files/Instructional Continuity_Detailed_Guidance.docx
} 


\section{Instructional Continuity Framework}

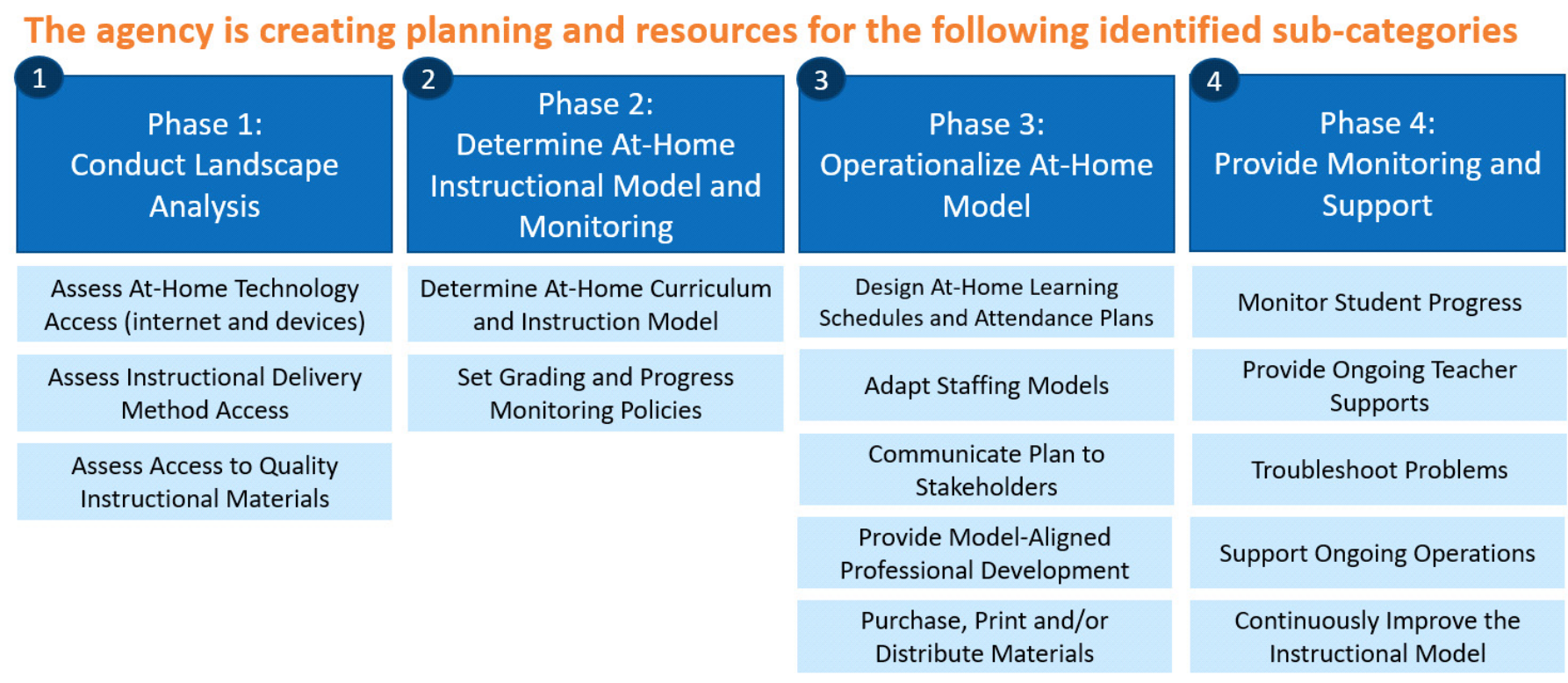

\section{$T=P$ A}

Figure 3: Four phase instructional continuity framework from the Texas Education Agency ${ }^{38}$

\section{Conclusion}

Crises focus our priorities. Some of the changes that schools are making during this pandemic may be worth continuing when normal times return. We appreciate that several states published recommended schedules that call for daily time for physical activity and the arts, even among states recommending a shortened day (see the San Antonio Case, for example). The benefits of exercise and creative expression for addressing stress and extended crises are well documented (S. Ahn \& Fedewa, 2011; Beauregard, 2014; Jansen \& LeBlanc, 2010; Meyer DeMott et al., 2017), and we applaud states for this emphasis. It is perhaps noteworthy that many school systems, when operating under a typical full-day schedule, do not allot daily time for physical activity and the arts. These are the kinds of changes that school systems may reflect upon after the pandemic: if America's children needed daily exercise and arts during hard times, why not in good times as well?

For all the rapid progress made by states in their policy guidance, important issues remain unresolved. From our findings, we offer three primary recommendations as state agencies proceed with this work. First, continue to center issues of equity, with increased guidance for special populations. While states have an admirable emphasis on students with disabilities, and hopefully a growing attention to the needs of ELLs, concrete guidance about how to serve these learners in challenging times remains nascent. Second, offer instructional guidance that recognizes the challenges and constraints of home-based, distance learning. States, districts, and schools will need to quickly learn how to bolster technological infrastructure in the houses, apartments, and shelters where children live. We observe that states are recommending divergent approaches on issues such as the risks and rewards of pursuing asynchronous over synchronous schedules, the question of whether to emphasize enrichment versus covering new material, and the new challenges posed by synchronous videoconferencing in school systems.

\footnotetext{
${ }^{38}$ San Antonio Texas Education Agency· (2020). Instructional Continuity Framework Detailed Guidance. https://tea.texas.gov/sites/default/files/Instructional_Continuity_Detailed_Guidance.docx
} 
It may be possible to rapidly evaluate different strategies towards these issues, shared best practices, and adjust course. Then, as schools crest the wave of an initial transition, more planning resources will need to be devoted to innovative approaches to remediating missed learning during the 2020-2021 academic year. Third, states should continue to offer clear, consolidated communications aimed at multiple target audiences. We encourage state agencies to be vocal and public about their most difficult challenges and important questions so that the education research community can partner to help address these issues.

As educators, we found the review of these 50 state-level guidance documents to be an encouraging, at times even heartwarming, exercise. The current challenges to the U.S. education system are unprecedented, and in every corner of the country, educational professionals are working together, displaying ingenuity, and centering issues of equity. This crisis demonstrates how essential schools are to our society, even as it reveals serious concerns about the extensive role that schools play in providing a safety net and social services to our country's most vulnerable children. We hope that in highlighting the diverse approaches and many exemplary practices found in state responses to extended school closures, we have provided useful guidance for addressing the challenging days ahead and preparing for future disruptions to schooling. 


\section{References}

Ahn, J., \& McEachin, A. (2017). Student Enrollment Patterns and Achievement in Ohio's Online Charter Schools. Educational Researcher, 46(1). 44-57. https://doi.org/10.3102/0013189X17692999

Ahn, S., \& Fedewa, A. L. (2011). A Meta-analysis of the Relationship Between Children's Physical Activity and Mental Health. Journal of Pediatric Psychology, 36(4), 385-397. https://doi.org/10.1093/jpepsy/jsq107

Inter-agency Network for Education in Emergencies (INEE) (2016). Psychosocial Support and Social and Emotional Learning for Children and Youth in Emergency Settings. New York, USA.

Anderson, M. (2019). Mobile Technology and Broadband 2019. Pew Research Center. file:/// Users/garron/Downloads/PI 2019.06.13 Mobile-Technology-and-Home-Broadband FINAL2.pdf

Bazzaz, D. (2020, March 9). Dispatches from parents: Northshore School District's first online-only day to prevent coronavirus spread. The Seattle Times. https://www.seattletimes.com/seattlenews/education/how-northshore-parents-handled-the-first-day-of-online-learning/

Beauregard, C. (2014). Effects of classroom-based creative expression programmes on children's well-being. The Arts in Psychotherapy, 41(3), 269-277. https://doi.org/10.1016/j.aip.2014.04.003

Charmaz, K. (2014). Constructing Grounded Theory (2nd ed.). SAGE Publications Ltd.

Collom, E. (2005). The Ins and Outs of Homeschooling: The Determinants of Parental Motivations and Student Achievement. Education and Urban Society, 37(3). 307-335.

https://doi.org/10.1177/0013124504274190

Cuban, L. (2009). Hugging the Middle?How Teachers Teach in an Era of Testing and Accountability (1st edition). Teachers College Press.

Dynarski, S. (2018, January 19). Online Courses Are Harming the Students Who Need the Most Help. The New York Times. https://www.nytimes.com/2018/01/19/business/online-courses-areharming-the-students-who-need-the-most-help.html

Fitzpatrick, B. R., Berends, M., Ferrare, J. J., \& Waddington, R. J. (2020). Virtual Illusion:

Comparing Student Achievement and Teacher and Classroom Characteristics in Online and Brickand-Mortar Charter Schools. Educational Researcher.

https://doi.org/10.3102/0013189X20909814

Gregory, E. R. (2005). "Curriculum and the status of physical education in homeschooling".

Teaching and Leadership - Dissertations. 36.

https://surface.syr.edu/tl etd/3

Hansen, J. D., \& Reich, J. (2015). Democratizing education? Examining access and usage patterns in massive open online courses. Science, 350(6265), 1245-1248. 
Hart, C. M. D., Berger, D., Jacob, B., Loeb, S., \& Hill, M. (2019). Online Learning, Offline Outcomes: Online Course Taking and High School Student Performance. AERA Open. https://doi.org/10.1177/2332858419832852

Ito, M., Gutierrez, K., Livingstone, S., Penuel, B., Rhodes, J., Salen, K., Schor, J., Sefton-Green, J., \& Watkins, S. C. (2012). Connected Learning: An Agenda for Research and Design. DML Research Hub. https://dmlhub.net/publications/connected-learning-agenda-for-research-and-design/index. $\underline{\mathrm{html}}$

Jansen, I., \& LeBlanc, A. G. (2010). Systematic review of the health benefits of physical activity and fitness in school-aged children and youth. International Journal of Behavioral Nutrition and Physical Activity, 7(40). https://doi.org/10.1186/1479-5868-7-40

Meyer DeMott, M. A., Jakobsen, M., Wentzel-Larson, T., \& Heir, T. (2017). A controlled early group intervention study for unaccompanied minors: Can Expressive Arts alleviate symptoms of trauma and enhance life satisfaction? Scandinavian Journal of Psychology, 58(6), 510-518.

Molnar, A., Miron, G., Elgeberi, N., Barbour, M. K., Huerta, L., Shafer, S. R., \& Rice, J. K. (2019). Virtual Schools in the U.S. 2019. National Education Policy Center. https://nepc.colorado.edu/ publication/virtual-schools-annual-2019

Plunkett, L., \& Gasser, U. (2016). Student Privacy and Ed Tech (K-12) Research Briefing (No. 201615). Berkman Center. https://papers.ssrn.com/sol3/papers.cfm?abstract id=2842800

Reykdal, C. (2020). BULLETIN NO. 016-20 STUDENT ENGAGEMENT AND SUPPORT. Washington Office of Superintendent of Public Instruction. https://www.k12.wa.us/sites/default/ files/public/bulletinsmemos/bulletins2020/COVID-19\%20Guidance\%20on\%20Online\%20 Learning Waivers School\%20Closures as\%20of\%20March\%206\%202020.pdf

Sandberg Patton, K. L., \& Reschly, A. L. (2013). Using Curriculum-Based Measurement to Examine Summer Learning Loss. Psychology in the Schools, 50(7), 738-753.

Schindler, M., \& Schiraldi, V. (2020, March 27). Let's keep youth justice from making the coronavirus worse. USA Today. https://www.usatoday.com/story/opinion/policing/2020/03/27/ coronavirus-lets-keep-youth-justice-making-pandemic-worse-column/2909458001/

Takahama, E. (2020, March 4). Northshore School District closes all schools for coronavirus concerns: 'We are no longer able to provide quality instruction.' The Seattle Times. https://www. seattletimes.com/seattle-news/education/northshore-school-district-closes-all-schools-beginningthursday-school-will-resume-online-monday/

Toto, J. (1994). How to Homeschool (Yes, You!) (1st ed.). Vital Issues Pr. 
United States Department of Education, Office for Civil Rights, \& Office of Special Education and Rehabilitative Services. (2020). Supplemental Fact Sheet Addressing the Risk of COVID-19 in Preschool, Elementary and Secondary Schools While Serving Children with Disabilities. https:// www2.ed.gov/about/offices/list/ocr/frontpage/fag/rr/policyguidance/Supple\%20Fact\%20 Sheet\%203.21.20\%20FINAL.pdf

Wolfman-Arent, A., \& Mezzacappa, D. (2020, March 18). Philly schools forbid graded 'remote instruction' during shutdown for equity concerns. WHYY. https://whyy.org/articles/philly-schoolsforbid-remote-instruction-during-shutdown-for-equity-concerns/

Xu, D., \& Jaggars, S. S. (2014). Performance Gaps Between Online and Face-to-Face Courses: Differences Across Types of Students and Academic Subject Areas. The Journal of Higher Education, 85(5). 633-659. https://muse.jhu.edu/article/553171 